\title{
Comparison of Human Eosinophils from Normals and Patients with Eosinophilia
}

\author{
David A. Bass, William H. Grover, Jon C. Lewis, Pamela Szejda, \\ Lawrence R. DeChatelet, and Charles E. MCCall, Departments of \\ Medicine, Biochemistry and Pathology, Bowman Gray School of Medicine, \\ Winston-Salem, North Carolina 27103
}

\begin{abstract}
A B S T RACT Previous studies of the biochemistry and physiology of eosinophils have relied upon cells obtained from patients with eosinophilia (EE). It is unknown whether such cells might have been activated or partially exhausted by the pathological state causing eosinophilia. We examined cell surface charge, membrane transport of deoxyglucose, activation of lysosomal acid phosphatase, and oxidative metabolism to provide a profile to compare EE with purified normal eosinophils (NE) and normal neutrophils.
\end{abstract}

Eosinophils or neutrophils were obtained in $>95 \%$ purity from normal individuals and patients with eosinophilia of diverse etiologies. Cell surface charge was determined by electrophoretic mobility in micromoles per second per volt per centimeter. Normal eosinophils demonstrated a surface charge of $2.46 \pm 0.03$. Stimulation of the cells by zymosan-activated serum (ZAS) reduced the surface charge to $1.82 \pm 0.02$. In contrast, the charge of "resting" EE was already reduced $(1.89 \pm 0.05)$ and was not altered by ZAS. Resting and stimulated neutrophils had a charge of $1.98 \pm 0.01$ and $1.69 \pm 0.02$, respectively.

Uptake of $\left[{ }^{3} \mathrm{H}\right] 2$-deoxyglucose has been shown to reflect carrier-facilitated hexose transport in granulocytes. Deoxyglucose uptake by resting $\mathrm{NE}$ and $\mathrm{NE}$ stimulated by ZAS was $2.40 \pm 0.40$ and $5.44 \pm 0.39$ (cpm $\times 10^{-3} / 2 \times 10^{5}$ eosinophils), respectively. Resting and stimulated $\mathrm{EE}$ demonstrated deoxyglucose uptake of $7.55 \pm 0.58$ and $15.3 \pm 0.6$, respectively.

Lysosomal acid phosphatase was determined by an electron microscopic cytochemical technique. In normal eosinophils and neutrophils, lysosomal acid phosphatase in mature cells is held in a latent form. Normal eosinophils demonstrated weakly positive acid phosphatase activity in $7.8 \pm 1.2 \%$ of the specific granules. Normal eosinophils, stimulated by opsonized staphylococci or the calcium ionophore

Received for publication 4 June 1980 and in revised form 28 July 1980.
A23187, develop rapid activation of acid phosphatase in $\sim 80 \%$ of the granules throughout the cells. Resting EE were usually already activated and demonstrated acid phosphatase in $48.6 \pm 8.6 \%$ of the granules (range, $2-95 \%$ granules positive; significant activation was observed in preparations in EE from 11 of 15 patients).

Oxidative metabolism was monitored by measurement of the hexose monophosphate shunt (HMPS) (metabolism of $1-\left[{ }^{14} \mathrm{C}\right]$ glucose to ${ }^{14} \mathrm{CO}_{2}$ ). Previous studies demonstrated that resting EE have an HMPS activity which is nearly that of stimulated neutrophils, yet EE remain capable of further 7-10-fold increase when stimulated by opsonized zymosan. In contrast, the HMPS of NE (resting and stimulated) was not significantly different from that of neutrophils.

Thus eosinophils obtained from patients with eosinophilia appear significantly activated when compared with normal eosinophils by the criteria of surface charge, activation of lysosomal acid phosphatase, membrane hexose transport, and hexose monophosphate shunt activities.

\section{INTRODUCTION}

Nearly all studies of eosinophil physiology have used cells obtained from patients with eosinophilia (EE). ${ }^{1}$ This has been necessitated by the small number of eosinophils in the blood of normal individuals and difficulties in isolating such cells for study. However, eosinophils from patients with eosinophilia of diverse causes, including allergies, parasitic infestations, or the hypereosinophilic syndrome, demonstrate morpho-

\footnotetext{
${ }^{1}$ Abbreviations used in this paper: AP, acid $\beta$-glycerophosphatase; DOG, 2-deoxy-D-glucose; EE, eosinophils obtained from patients with eosinophilia; HBSSg, Hanks' balanced salt solution containing $0.1 \%$ gelatin; HETE, monohydroxyeicosatetraenoic acid; HMPS, hexose monophosphate shunt; NDGA, nordihydroguaiaretic acid; NE, eosinophils obtained from normal donors; PBS, Dulbecco's phosphate-buffered saline; ZAS, zymosan-activated serum.
} 
logic abnormalities such as partial degranulation and/ or vacuolation of the cells (1-5), and increased segmentation of the nuclear lobes, which might reflect an increased age of the cells (6).

The morphologic abnormalities of $\mathrm{EE}$ have suggested that such eosinophils might be stimulated, activated, or (partially) exhausted by a response to the pathologic process causing the eosinophilia. However, comparisons of $\mathrm{EE}$ and eosinophils obtained from normal donors (NE) have been few and often contradictory. Such studies have noted that EE may have increased receptors for $\operatorname{IgG}(4,5,7,8)$ or $\mathrm{C} 3 \mathrm{~b}(8)$ but other studies have found normal $\operatorname{IgG}(9)$ and $\mathrm{C} 3 \mathrm{~b}(4,5,7)$ receptors. Spry and Tai (5) studied EE from three patients and found increased phagocytosis of IgG- or C3b-coated erythrocytes, yet Grover et al. (10) found that EE had a lower phagocytic rate than NE (10). Whereas Butterworth et al. (11) originally observed reduced ability of EE to damage schistosomula (monitored by chromium release), more recent studies, using morphologic damage and supravital dye uptake, indicated $\mathrm{EE}$ were more potent than $\mathrm{NE}$ in the killing of schistosomula (12). Part of these variable results may be due to differences in techniques. Alternatively, EE, obtained from patients with diseases of variable etiology and severity, might display a spectrum of abnormalities.

The present studies were undertaken to provide a profile that might facilitate comparison of $\mathrm{NE}$ with $\mathrm{EE}$ and normal neutrophils. The profile included studies of membrane surface charge, membrane transport of 2deoxyglucose, state of activation of lysosomal acid phosphatase, and, as a monitor of oxidative metabolism, hexose monophosphate shunt activity.

\section{METHODS}

Preparation of human leukocytes. Heparinized blood was obtained from normal volunteers (peripheral blood eosinophil count $<300 / \mathrm{mm}^{3}$ ) and volunteers with eosinophilia (eosinophil counts $422-36,000 / \mathrm{mm}^{3}$ ) resulting from allergic rhinitis, eczema, acute drug reactions, strongyloidiasis, eosinophilic gastroenteritis, and the hypereosinophilic syndrome. Leukocytes were initially isolated using a modification of a method of Boyum (13). Blood was layered over an equal volume of 9.6\% sodium metrizoate and 5\% Ficoll (Isolymph, GallardSchlesinger Chemical Mfg. Corp., Carle Place, N. Y.). Sedimentation by gravity at room temperature was allowed to proceed for 30-40 min. The leukocyte-rich plasma was drawn off and the leukocytes washed in calcium and magnesiumfree Hanks' balanced salt solution containing $0.1 \%$ gelatin (HBSSg) (Gibco Laboratories, Grand Island Biological Co., Grand Island, N. Y.). For cytochemical and chemotactic studies, these preparations of mixed leukocytes were resuspended to $5 \times 10^{6}$ cell $/ \mathrm{ml}$ in $\mathrm{HBSSg}$. The other assays used $\mathrm{EE}$ or $\mathrm{NE}$ isolated in $>95 \%$ purity.

For preparation of neutrophils, granulocyte and mononuclear cell populations were separated by layering leukocyte-rich plasma over an equal volume of Isolymph followed by centrifugation at $400 \mathrm{~g}$ for $40 \mathrm{~min}$. The granulocyte- containing pellet was washed with $\mathrm{Ca}^{++}-\mathrm{Mg}^{++}$-free $\mathrm{HBSSg}$. Total leukocytes, differential (using Wright's stain) and absolute eosinophil counts (using Discombe's method) were performed and the preparations diluted to the desired leukocyte concentration.

Eosinophils were purified by modifications of the methods of Grover et al. (10) and Vadas et al. (14). Linear gradients of $15-30 \%$ sodium metrizamide (Gallard-Schlesinger Chemical Mfg. Corp.) or Hypaque (Winthrop Laboratories, Freehold, N. J.) were prepared using RPMI or Tyrode's buffer containing $0.1 \%$ gelatin and supplemented with deoxyribonuclease (Calbiochem-Behring Corp., American Hoechst Corp., San Diego, Calif.), $10 \mathrm{mg} /$ liter as diluent. $10^{8}$ leukocytes were layered over each $10-\mathrm{ml}$ gradient and centrifuged at $900 \mathrm{~g}$ for $15 \mathrm{~min}$. Fractions $(0.5 \mathrm{ml})$ were removed, and the number and purity of eosinophils in each fraction determined. In all preparations, $>95 \%$ leukocytes were viable, as judged by trypan blue exclusion.

Granulocyte cell surface charge. A modification of the method of Gallin et al. (15) was used. Isolated granulocytes were incubated for $1 \mathrm{~h}$ in Dulbecco's phosphate-buffered saline (PBS) containing 50\% fresh, unactivated human serum, or zymosan-activated serum (ZAS). The cells were then thrice washed (by centrifugation) in $10 \mathrm{ml} 0.013 \mathrm{M}$ phosphate buffer (16) $\mathrm{pH} 7.40$ at $30^{\circ} \mathrm{C}$ with sodium hypaque added to a density of 1.07 . The washed cells were placed in the cleansed chamber $\left(10 \% \mathrm{NaOH}\right.$ in $70 \%$ ethanol, $\left.\mathrm{H}_{2} \mathrm{O}, 1 \% \mathrm{HCl}, \mathrm{H}_{2} \mathrm{O}\right)$ of a microscope-monitored, calibrated electrophoresis apparatus (Grant Instruments Ltd., Cambridge, England), immersed in a constant temperature water bath, and prefocused by means of a micrometer (Thomas Mercer Limited, St. Albans, England) to a constant depth to avoid electroosmotic streaming phenomena $(16,17)$. Uncharged liposome immobility in the system confirmed that particle charge was responsible for mobility at this focus point. The mobility $(\mu)$ of a cell population was determined by the formula:

$$
\mu=\frac{l}{\bar{x} \frac{\text { IR }}{q}},
$$

where $l=$ distance in centimeters, $\bar{x}=$ average time to cover distance $l$ in to and fro determinations, $\mathrm{I}=$ current in amperes, $R=$ specific resistance, and $q=$ cross sectional area of the chamber (square centimeters). Cell mobility was determined for at least 25 separate cells (16) of each population. By this calculation, the charge of human erythrocytes was $2.66 \pm 0.02 \mu \mathrm{m} / \mathrm{s}$ per $\mathrm{V}$ per $\mathrm{cm}$, in agreement with previous studies (17).

Assay of hexose uptake. Uptake of $\left[{ }^{3} \mathrm{H}\right] 2$-deoxy-D-glucose (DOG) was assessed by a modification of a previously described technique (18). $\left[{ }^{3} \mathrm{H}\right]$ DOG $(\mathrm{sp}$ act $50 \mathrm{mCi} / \mathrm{mmol}$ ) (New England Nuclear, Boston, Mass.) was diluted to 50 $\mu \mathrm{Ci} / \mathrm{ml}$ in $\mathrm{H}_{2} \mathrm{O}$ and stored at $-20^{\circ} \mathrm{C}$. As required, aliquots were further diluted to $5 \mu \mathrm{Ci} / \mathrm{ml}$ with PBS. Triplicate assays were performed in $1.5 \mathrm{ml}$ polypropylene test tubes (Eppendorf, Brinkmann Instruments, Inc., Westbury, N. Y.) in a final volume of $0.3 \mathrm{ml}$ containing $2 \times 10^{5}$ granulocytes in glucosefree Dulbecco's PBS containing $0.9 \mathrm{mM} \mathrm{Ca}^{++}$and $0.5 \mathrm{mM}$ $\mathrm{Mg}^{++}$. Granulocytes were preincubated for $15 \mathrm{~min}$ with substances to be tested at $37^{\circ} \mathrm{C}$ in a shaking water bath. Uptake was initiated by addition of $0.5 \mu \mathrm{Ci}\left[{ }^{3} \mathrm{H}\right] \mathrm{DOG}$ (10 $\mathrm{nMol}$, with a total activity of $388,000 \mathrm{cpm}$ ) and stopped after $60 \mathrm{~min}$ by addition of $1 \mathrm{ml}$ iced PBS, and the samples were then centrifuged (Beckman Microfuge B) at 9,000 $\mathrm{g}$ for $20 \mathrm{~s}$. The pellets were washed with $1 \mathrm{ml}$ iced PBS and recentrifuged. The supernate was removed by aspiration and 
the pellets and tubes were placed in scintillation vials containing $10 \mathrm{ml}$ Aquasol (New England Nuclear). Radioactivity was determined on a Beckman scintillation counter (Beckman Instruments, Inc., Palo Alto, Calif.). Values were expressed as counts per minute $/ 2 \times 10^{5}$ granulocytes.

The use of DOG to assess hexose transport depends upon the intracellular phosphorylation of DOG by hexokinase. Hexokinase activity, determined as described previously (18), was not altered by incubation of eosinophils in $2 \% \mathrm{ZAS}$, $10 \mu \mathrm{M}$ nordihydroguaiaretic acid (NDGA) or $10 \mu \mathrm{M}$ indomethacin.

Cytochemical determination of acid phosphatase activity. A modification of the Gomori technique (19) was used. Leukocytes were combined for 5 min with 8 vol of cold fixative composed of $0.5 \%$ glutaraldehyde plus $5 \%$ paraformaldehyde buffered to $\mathrm{pH} 7.2$ with $0.1 \mathrm{M}$ cacodylate. Subsequent to fixation the cells were thrice washed over a period of $1 \mathrm{~h}$ in cold $0.1 \mathrm{M}$ cacodylate $\mathrm{pH} 7.2$ containing $2 \%$ sucrose. Before reaction for acid phosphatase, a wash was done using $0.05 \mathrm{M}$ Tris-maleate buffer $\mathrm{pH} 5.0$ and the enzyme reaction conducted for $1 \mathrm{~h}$ at $37^{\circ} \mathrm{C}$. The reaction medium consisted of $0.05 \mathrm{M}$ Tris-maleate buffer containing $0.3 \%$ sodium $\beta$-glycerophosphate and lead nitrate as the capture ion. Control reactions for acid phosphatase included treatment of cells with 0.5 $\mathrm{mg} / \mathrm{ml}$ sodium fluoride prior to enzyme reaction or the omission of the $\beta$-glycerophosphate substrate from the medium.

Hexose monophosphate shunt activity. The oxidation of 1-[ $\left[{ }^{14} \mathrm{C}\right]$ glucose (New England Nuclear) to ${ }^{14} \mathrm{CO}_{2}$ was determined by modification of the previously described technique (20) to allow use of smaller numbers $\left(2-5 \times 10^{5}\right)$ of granulocytes. Each flask contained $0.2 \mu \mathrm{Ci}$ (sp. act. $50 \mathrm{mCi} / \mathrm{mmol}$ ) labeled and $30 \mu \mathrm{g}$ unlabeled glucose in a final volume of $1 \mathrm{ml}$ of PBS. Appropriate flasks contained zymosan which had been opsonized with fresh pooled human serum. The reaction was initiated by addition of cells in PBS and incubated for 60 min. The reaction was stopped by the addition of $1 \mathrm{ml}$ of $5 \%$ trichloroacetic acid. The ${ }^{14} \mathrm{CO}_{2}$ liberated during the reaction was collected and quantitated as previously described (20). Results are expressed as counts per minute per $5 \times 10^{5}$ cells after subtracting background (counts per minute in flasks lacking cells).

Migration-under-agarose assay. Random migration and chemotaxis were assessed by a modification of the migrationunder-agarose assay reported previously (21). Series of three wells, $2.4 \mathrm{~mm}$ Diam and $2.4 \mathrm{~mm}$ apart, were cut (with a template) in $60 \times 15-\mathrm{mm}$ tissue culture dishes (Falcon Labware, Div. Becton, Dickinson \& Co., Oxnard, Calif.) containing $5 \mathrm{ml}$ of $1.2 \%$ agarose in minimal essential medium supplemented with $10 \%$ fetal calf serum. Granulocytes $\left(10^{6}\right.$ per well) were added to the center well, and $10 \mu \mathrm{l}$ of ZAS or PBS added to the outer wells. The plates were incubated for $3 \mathrm{~h}$, and fixed with methanol and formalin. The agarose was removed and the cells stained with haematoxylin and Biebrich Scarlet as described previously (22). The stain allowed differentiation of migrating eosinophils and neutrophils (the mixed granulocyte preparations used contained 45-90\% eosinophils). The leading edge (linear distance from the edge of the well to the advancing edge of migrating cells) toward the ZAS (chemotaxis) or PBS (random motility) was measured with an inverted microscope (Olympus CK, Olympus Corporation of America, New Hyde Park, N. Y.) equipped with a linear reticle. Six determinations were made on each granulocyte preparation.

Stimuli and inhibitors. ZAS was prepared by incubating $2 \mathrm{ml}$ of fresh serum with twice-washed zymosan (Schwartz/ Mann, Div. Becton, Dickinson \& Co., Orangeburg, N. Y.) at $37^{\circ} \mathrm{C}$ for $30 \mathrm{~min}$, with removal of the zymosan by centrifugation at $1,000 \mathrm{~g}$ for $10 \mathrm{~min}$. Partially purified C5a was prepared as described previously (23) by CM-cellulose and Sephadex G-100 fractionation of $300 \mathrm{ml}$ of serum containing $1 \mathrm{M} \epsilon-$ aminocaproic acid that had been activated with zymosan.

5,8,11,14-Eicosatetraynoic acid (ETYA) (a gift of Dr. W. E. Scott, Hoffmann-La Roche, Inc., Nutley, N. J.) was dissolved in dimethylsulfoxide (DMSO) and stored at $-70^{\circ} \mathrm{C}$ under nitrogen. NDGA (double recrystallized, a gift of Dr. E. J. Goetzl, Harvard Medical School, Boston, Mass.) and indomethacin (Sigma Chemical Co., St. Louis, Mo.) were dissolved in DMSO. At the maximal concentrations used $(<0.3 \%)$, DMSO did not affect viability (assayed by trypan blue exclusion and lactate dehydrogenase release) or deoxyglucose uptake of granulocytes.

Statistical analysis. Unless specified otherwise, data are expressed as means $\pm S E$. Significance was determined by the unpaired Student $t$ test (to compare responses of separate granulocyte preparations) or paired Student $t$ test (to examine effects of stimuli or inhibitors). Linear regression was determined by the method of least mean squares.

\section{RESULTS}

Purification of eosinophils. The success of isolation of eosinophils depended to some degree on the level of eosinophils in the blood of the donor. NE could be purified by density gradient centrifugation using either Hypaque or metrizamide with either RPMI or Tyrode's buffer as diluent. These provided a recovery of $\sim 30 \%$ at a purity of $95-100 \%$. Eosinophil recovery from patients with eosinophilia was less predictable. Patients with modest eosinophilia $\left(350-1,000 / \mathrm{mm}^{3}\right)$ provided the most reliable source. Eosinophils from such patients could often be purified by either density gradient, but the use of metrizamide diluted with Tyrode's buffer provided more consistent yields. Moreover, although preliminary experiments with neutrophils indicated that cell charge was unaffected by sedimentation through Hypaque/HBSS, deoxyglucose uptake of such cells was stimulated by the isolation procedure. Purification over metrizamide/Tyrode's did not cause stimulation of deoxyglucose uptake if the cells were rapidly washed and placed in HBSSg.

Eosinophils could only occasionally be isolated from patients with marked eosinophilia. Such EE usually sedimented with the neutrophils in the sample. Thus, marked (and occasionally modest) eosinophilia may be associated with a shift in the density of the cells (at least within the environment of the gradient). The studies of EE purified by density gradient centrifugation thus unavoidably select that population of eosinophils whose density remains greater than the neutrophils in the preparation. This might cause a selection of the more normal cells in the population and thereby would underestimate the observed differences between NE and EE.

Cell charge. Normal eosinophils had a significantly greater negative surface charge than normal neutrophils (Tables I and II). Both neutrophils and NE reduced their surface charge following stimulation with ZAS. In contrast, the charge of resting EE was not 
TABLE I

Surface Charge and Motility of EE, NE, and Neutrophils

\begin{tabular}{|c|c|c|c|c|}
\hline & \multicolumn{2}{|c|}{ Surface charge ${ }^{*}$} & \multirow{2}{*}{$\begin{array}{l}\text { Random } \\
\text { motility! }\end{array}$} & \multirow{2}{*}{$\begin{array}{c}\text { Chemotaxis } \\
\text { to ZAS } t\end{array}$} \\
\hline & Resting & ZAS & & \\
\hline $\mathrm{NE}$ & $2.46 \pm 0.03(11)$ & $1.82 \pm 0.02(3)$ & $\mathrm{ND} \S$ & ND \\
\hline $\mathrm{EE}$ & $1.89 \pm 0.07(6)$ & $1.91 \pm 0.02(3)$ & $0.79 \pm 0.13(3)$ & $1.77 \pm 0.24$ \\
\hline Neutrophils & $1.98 \pm 0.01(11)$ & $1.69 \pm 0.02(6)$ & $0.71 \pm 0.04$ & $1.86 \pm 0.16(3)$ \\
\hline
\end{tabular}

* Data are means $\pm \mathrm{SE}$ of $(n)$ separate eosinophil or neutrophil preparations. Charge is expressed as micromoles per second per volt per centimeter and was determined on cells preincubated in fresh normal serum or ZAS.

$\ddagger$ Determined by the migration-under-agarose technique, measuring the leading edge of migrating neutrophils and eosinophils in millimeters. Means $\pm \mathrm{SE}$ of $(n)$ separate granulocyte preparations. Each preparation was studied in sextuplicate.

$\S \mathrm{ND}$, not done.

significantly different from that of stimulated NE. Moreover, stimulation of EE with ZAS caused no significant change in the charge of the cells (Table I).
Although chemotactic factors cause a reduced cell charge of normal neutrophils $(15,24)$ and eosinophils (Table I), it appears that this phenomenon is not

TABLE II

Surface Charge, Deoxyglucose Uptake, and Acid Phosphatase Activity of EE

\begin{tabular}{|c|c|c|c|c|c|}
\hline \multirow[b]{2}{*}{ Diagnosis } & \multirow{2}{*}{$\begin{array}{l}\text { Peripheral blood } \\
\text { eosinophils } / \mathrm{mm}^{3}\end{array}$} & \multirow{2}{*}{$\begin{array}{l}\text { Surface } \\
\text { charge }\end{array}$} & \multicolumn{2}{|c|}{ Deoxyglucose uptake } & \multirow{2}{*}{$\begin{array}{c}\mathrm{AP} \\
\text { activity }\end{array}$} \\
\hline & & & Resting & ZAS & \\
\hline \multirow[t]{9}{*}{ Hypereosinophilic syndrome } & 3,570 & - & 7,983 & 18,042 & 95 \\
\hline & 4,408 & 1.95 & 6,603 & 11,717 & - \\
\hline & 3,430 & - & 7,261 & 14,226 & - \\
\hline & 4,160 & - & 6,044 & 11,385 & - \\
\hline & 2,899 & - & 10,645 & - & - \\
\hline & 7,225 & - & 6,787 & 13,431 & - \\
\hline & 2,108 & - & 4,770 & 10,008 & - \\
\hline & 2,800 & - & 6,964 & 23,330 & - \\
\hline & 4,700 & - & 8,877 & - & - \\
\hline Eosinophilic gastroenteritis & 1,380 & - & 7,772 & - & 52 \\
\hline \multirow[t]{2}{*}{ Strongyloidiasis } & 2,825 & 2.08 & 9,206 & 20,019 & - \\
\hline & 3,200 & 1.84 & - & - & - \\
\hline Eosinophilic fasciitis & 866 & - & - & - & 10 \\
\hline \multirow[t]{2}{*}{ Pulmonary eosinophilia } & 4,539 & 2.06 & 7,886 & 14,545 & 40 \\
\hline & 1,622 & - & - & - & 75 \\
\hline \multirow[t]{5}{*}{ Atopy } & 800 & - & 7,590 & - & - \\
\hline & 539 & - & - & - & 78 \\
\hline & 750 & - & - & - & 92 \\
\hline & 722 & - & - & - & 12 \\
\hline & 638 & - & - & - & 14 \\
\hline \multirow[t]{3}{*}{ Drug reaction } & 422 & - & - & - & 38 \\
\hline & 1,600 & - & - & - & 28 \\
\hline & 1,408 & 1.66 & - & - & - \\
\hline (eosinophilic lymphadenitis) & 798 & 1.78 & - & - & - \\
\hline \multirow[t]{4}{*}{ Unknown-chronic eosinophilia } & 970 & - & 4,605 & 10,520 & 2 \\
\hline & 1,500 & - & 4,215 & 14,005 & 95 \\
\hline & 555 & - & - & - & 73 \\
\hline & 443 & - & - & - & 26 \\
\hline
\end{tabular}


necessary for a chemotactic response. EE, which did not decrease surface charge when exposed to ZAS, demonstrated a chemotactic response to ZAS that was similar to that of normal neutrophils (Table I). The large number of cells required for the migration-underagarose assay prevented the study of chemotaxis by NE.

Uptake of $\left[{ }^{3} H\right] D O G$. In separate studies, ${ }^{2}$ we have found that uptake of $\left[{ }^{3} \mathrm{H}\right] D O G$ reflects carrier-facilitated hexose transport in eosinophils, as reported previously in neutrophils (18). DOG uptake was saturable, stereospecific (inhibited by $>95 \%$ by $10 \mathrm{mM}$ D-glucose but unchanged by $10 \mathrm{mM}$ L-glucose) and inhibited by cytochalasin B, all of which are characteristics of carrier-facilitated hexose transport in other tissues (25). Uptake of DOG was essentially linear during the period of incubation. Once transported into the cell, deoxyglucose is nearly irreversibly phosphorylated and thereby is trapped within the cell. Hexokinase activities of resting and stimulated cells were equal. A small portion $(<10 \%)$ of transported DOG may be metabolized (26) and the data may thus slightly underestimate the differences between resting and stimulated cells. The present studies extend these observations to compare the hexose transport of $\mathrm{EE}$ and NE.

Uptake of DOG by resting EE was approximately thrice that of NE (Fig. 1, Table II). Upon stimulation by ZAS, both EE and NE demonstrated a comparable further enhancement of DOG uptake. Since the uptake of DOG by resting eosinophils provided a readily quantifiable assessment of the possible in vivo stimulation of these cells, it was examined further. Separate studies (27) suggested that stimulation of DOG uptake in vitro might be linked to release of membrane bound arachidonic acid and its subsequent metabolism via the lipoxygenase pathway. We therefore examined whether inhibitors of arachidonic acid metabolism would affect DOG uptake. The effects of $10 \mu \mathrm{M}$ NDGA (a lipoxygenase inhibitor [28, 29]) and $10 \mu \mathrm{M}$ indomethacin (a cyclooxygenase inhibitor [30]) were examined. The effects of these agents were studied by initiating DOG uptake after 15 min preincubation of the cells in PBS or PBS containing the inhibitor at $37^{\circ} \mathrm{C}$. NDGA caused a suppression of DOG uptake by resting eosinophils, to $60.8 \%$ of control levels, and, in contrast, indomethacin enhanced DOG uptake of unstimulated cells to $144 \%$ of control levels. Moreover, the suppression of DOG uptake by NDGA or enhancement of uptake by indomethacin was related to the activity of hexose transport of the resting eosinophils (Fig. 2). Thus, the resting DOG uptake correlated with the net suppression caused by NDGA $(r=0.94$,

\footnotetext{
${ }^{2}$ Bass, D. A., J. T. O'Flaherty, E. J. Goetzl, P. Szejda, and C. E. McCall. Stimulation of hexose uptake of human eosinophils by chemotactic factors and by arachidonic acid. Manuscript in preparation.
}

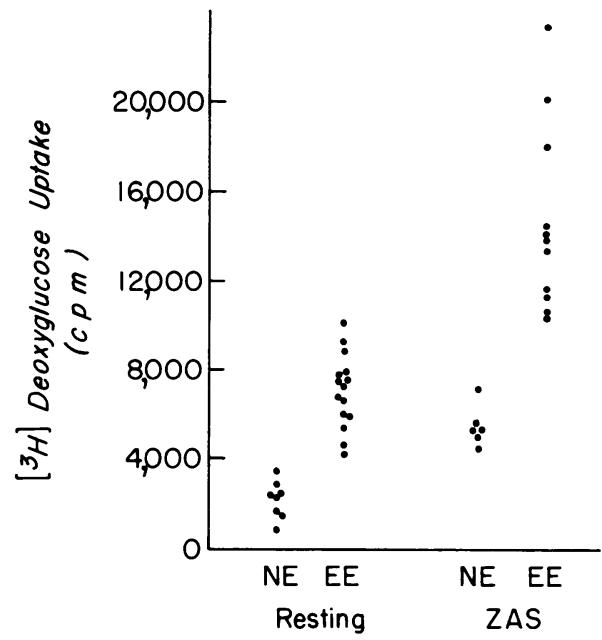

FIGURE 1 Deoxyglucose uptake of NE and EE after preincubation for $15 \mathrm{~min}$ in PBS (resting) or PBS containing $1.6 \%$ ZAS. Each point is the mean of triplicate determinations from a separate preparation of purified eosinophils.

$P=0.0002, n=8)$ and, conversely, correlated with the enhancement of uptake produced by indomethacin $(r=0.84, P<0.001, n=8)$.

Acid phosphatase activity. In normal, mature eosinophils, acid $\beta$-glycerophosphatase (AP) within the specific granules appears to be bound in an inactive or "latent" form $(31,32)$. We recently examined

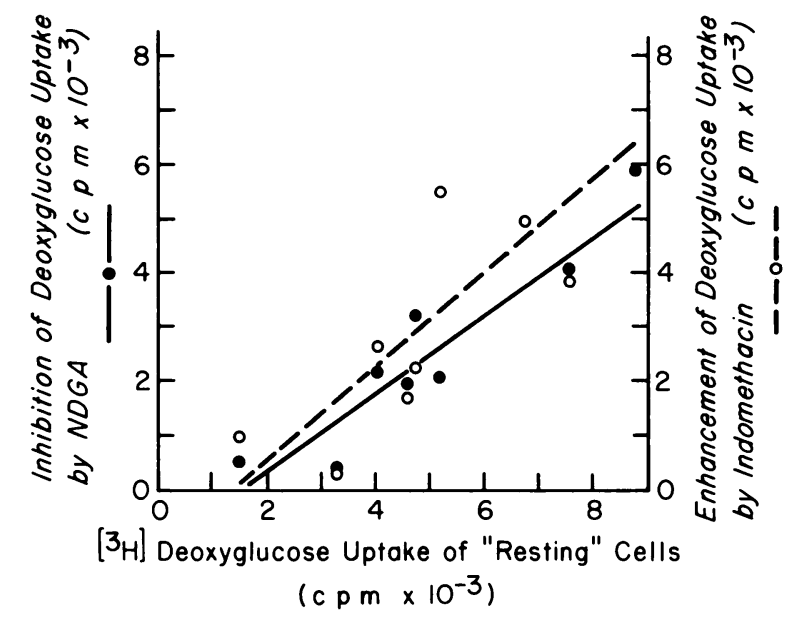

FIGURE 2 Correlation between the DOG uptake of resting eosinophils with the net suppression of the resting uptake by $10 \mu \mathrm{M}$ NDGA and the net enhancement of resting uptake by $10 \mu \mathrm{M}$ indomethacin. Before initiation of DOG uptake, purified eosinophils were preincubated for $15 \mathrm{~min}$ in PBS alone or PBS containing $10 \mu \mathrm{M}$ NDGA or $10 \mu \mathrm{M}$ indomethacin. The effect of NDGA is expressed as the counts per minute per $2 \times 10^{5}$ cells in PBS minus the counts per minute of cells in NDGA. The effect of indomethacin is the counts per minute of cells in indomethacin minus the counts per minute of cells in PBS. Each point is the mean of triplicate determinations made on separate eosinophil preparations. 


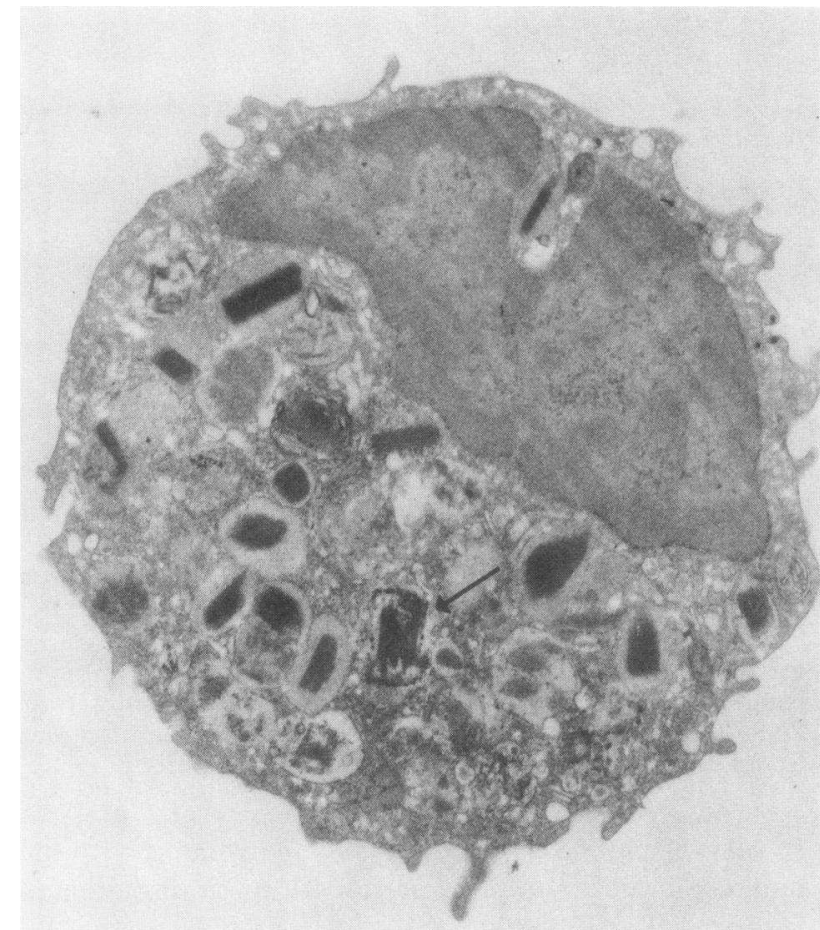

30

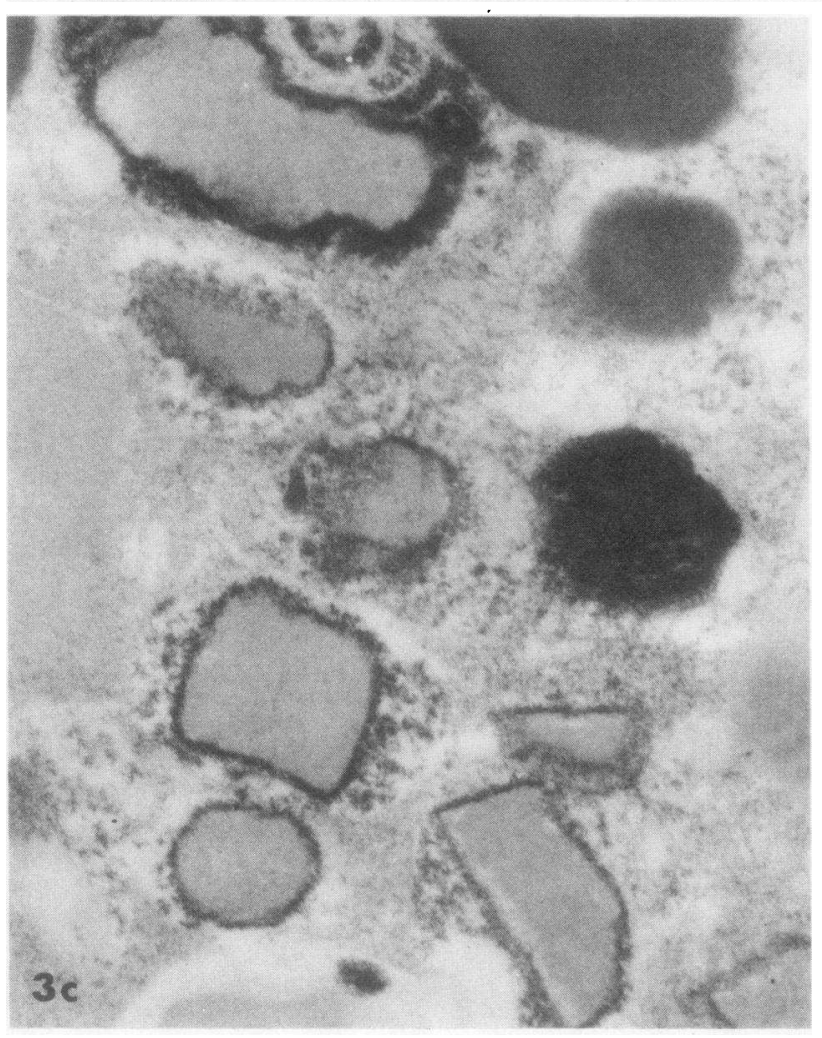

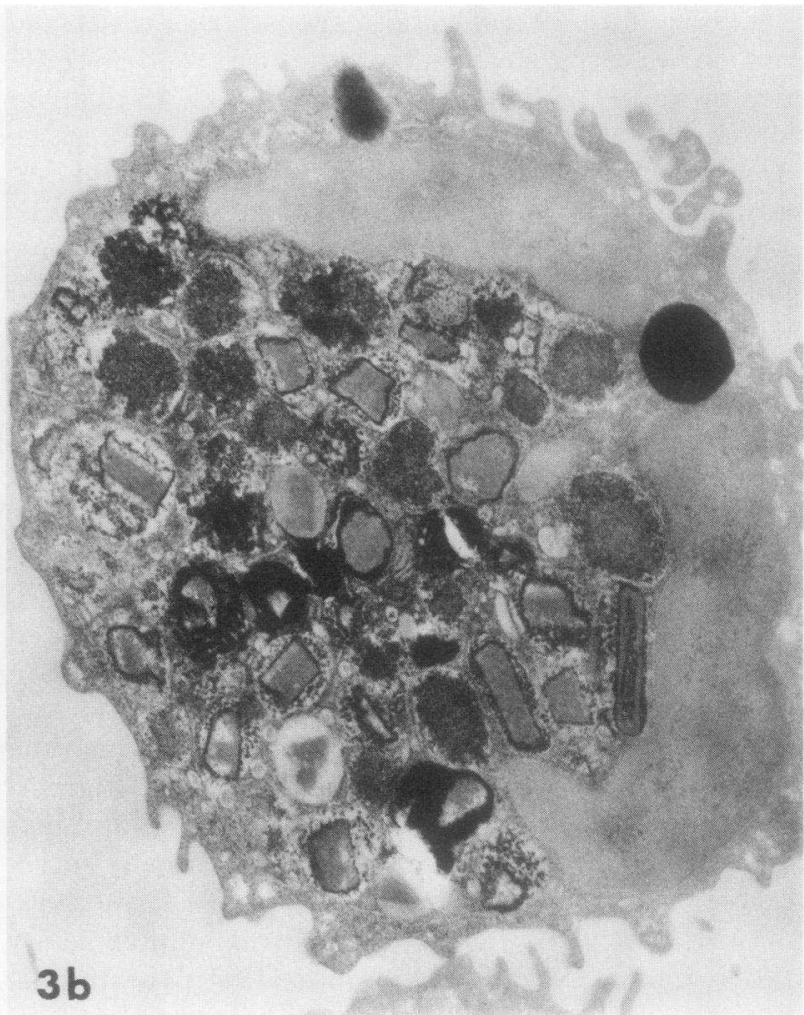

FIGURE 3 Eosinophils showing acid phosphatase reaction. (a) Deposition of enzyme product (arrow) representative of that found in normal cells, $\times 13,500$. (b) A highly reactive cell representative of those found in eosinophilia, $\times 15,500$. (c) High magnification micrograph showing reaction product localization in the granule matrix, $\times 44,000$. 
cytochemically demonstrable AP activity in normal eosinophils (33). Resting NE had AP activity (which was usually weak) in only $7.8 \pm 1.2 \%$ (mean $\pm \mathrm{SE}, n$ $=8$ ) of the granules. However, stimulation of the NE by opsonized staphylococci, phorbol myristate acetate or the ionophore A23187 caused an activation of cytochemically demonstrable AP throughout the granules of the cell (mean $\sim 75 \%$ of granules markedly positive with each stimulus) (33). The response was rapid and occurred within the time required for fixation of the cells by glutaraldehyde (reported to be $<30 \mathrm{~s}$ ) (34). In contrast with these observations, eosinophils obtained from patients with eosinophilia demonstrated variable amounts of AP reactivity in the "unstimulated" cells (Fig. 3, Table II). From 2 to 95 (mean \pm SE, 48.6 \pm 8.6 , $n=15) \%$ of the granules of such cells were positive for AP and the deposition of lead phosphate reactant was often intense (Fig. 4). If the normal range is defined as $1.2-14.4 \%$ of granules AP positive (mean $\pm 2 \mathrm{SD}$ ), 11 of 15 preparations of $\mathrm{EE}$ demonstrated significant AP activation.

Hexose monophosphate shunt (HMPS) activity. The resting activity of the HMPS of EE has been reported to be significantly increased above that of normal neutrophils $(20,35,36)$. In fact, the resting activity of EE may approach the HMPS of stimulated neutrophils, yet EE have the capability for a further 7-10-fold increase when stimulated by opsonized zymosan (20). In contrast with these observations, the HMPS of normal eosinophils was not significantly different from that of normal neutrophils, both in resting cells and cells stimulated by opsonized zymosan (Table III).

\section{DISCUSSION}

EE appear to be "stimulated" or "activated" when compared with NE by each of the criteria examined, cell surface charge, hexose transport, lysosomal AP activity, and oxidative metabolism. The degree of activation was not related to the cause or magnitude of the eosinophilia, or the clinical state of the patient (although longitudinal studies of patients have not been performed). Each of these responses offer certain advantages and disadvantages for possible elucidation of the altered physiology and functions of EE.

Acid phosphatase is cytochemically demonstrable within the homogeneous granules of immature, bone marrow eosinophils (32). However, studies of mature eosinophils have reported little or no cytochemical AP in the specific granules, although it is demonstrable biochemically and sediments with the specific granules (31). The change from an unmasked to a latent form occurs coincidently with appearance of typical crystalloids in specific granules (32). The latent AP of mature $\mathrm{NE}$ can be activated by stimulation of $\mathrm{NE}$ in vitro (33).

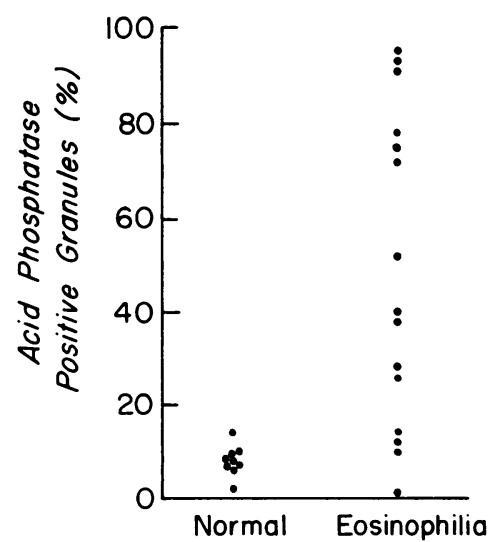

FIgUre 4 Acid phosphatase activity of NE and EE, expressed as the percentage of specific granules that demonstrated AP activity. Each point represents the value for a separate eosinophil preparation. A minimum of 200 granules (in most experiments, 500 granules) were counted for each preparation.

In contrast, the AP of EE was already activated in 11 of 15 preparations. Although the AP activity of EE could reflect the presence of immature eosinophils in the blood of such patients, this seems unlikely due to the following considerations: $(a)$ the specific granules of EE appeared mature, with normal crystalloids, and (b) EE demonstrate increased nuclear segmentation (6) rather than the decreased segmentation expected of immature cells. The data are more suggestive of an activation of AP of eosinophils in vivo during eosinophilia. The AP technique has the advantage of using mixed leukocyte preparations and thereby avoids any artifacts incurred by purification of the eosinophils in vitro. However, the expense of electron microscopic cytochemistry limits its use as a model to characterize the activating mechanism(s) of EE.

The HMPS of NE was equal to that of normal neutrophils, in contrast with previous reports of more

TABLE III

Oxidation of $I-\left[{ }^{14} C\right] G$ lucose by Normal Eosinophils and Neutrophils

\begin{tabular}{|c|c|c|c|c|}
\hline & \multicolumn{4}{|c|}{${ }^{14} \mathrm{CO}_{2}$ Released $\left(\mathrm{cpm} / 5 \times 10^{5}\right.$ cells $)$} \\
\hline & \multicolumn{2}{|c|}{ Eosinophils } & \multicolumn{2}{|c|}{ Neutrophils } \\
\hline & Resting* & Zymosan & Resting & Zymosan \\
\hline Exp. 1 & 1,018 & 6,518 & 480 & 4,525 \\
\hline Exp. 2 & 755 & 13,682 & 652 & 10,930 \\
\hline Exp. 3 & 345 & 6,470 & 307 & 6,247 \\
\hline
\end{tabular}

* Data are in cpm $/ 5 \times 10^{5}$ cells (after subtracting counts per minute of control flasks lacking cells) and are means of closely agreeing triplicate determinations. Eosinophil and neutrophil preparations were run in parallel. 
active oxidative metabolism of eosinophils from patients with marked eosinophilia. However, the HMPS of EE from two patients with modest eosinophilia was not significantly greater than that of NE (data not shown). Two possible explanations for these observations include either $(a)$ the activation of oxidative metabolism only occurs in patients with marked eosinophilia or $(b)$ the purification of EE by density gradient centrifugation selects the more nearly normal eosinophils (those whose density remains distinct from that of neutrophils in the gradient) that do not display activated oxidative metabolism. The data suggest that activation of oxidative metabolism is separable from activation of cell charge or hexose transport, which were observed in EE purified from patients with modest eosinophilia.

The measurement of cell charge or, in particular, hexose transport may provide the preferable models for further study of mechanisms of activation of EE. Each was altered in EE isolated from patients with modest eosinophilia. For example, cell charge of EE was significantly less than that of $\mathrm{NE}$ and was, in fact, equal to that of NE stimulated in vitro by ZAS. The mechanism of this alteration in cell charge is uncertain. Gallin (24) reported that a decreased surface charge of neutrophils was caused by diverse membrane stimulants and correlated with the release of lysozyme. It is doubtful that degranulation of lysozyme is related to the altered charge of eosinophils, as eosinophils do not contain lysozyme (31). Alternatively, Gallin (24) proposed that the reduced surface charge might be due to an increased submembranous content of calcium, observed in stimulated neutrophils (37). Such increased local calcium could relate to other functional responses through a series of membrane events including activation of calcium-dependent phospholipase $A_{2}$, cleavage of arachidonic acid from membrane phospholipids and subsequent generation of bioactive metabolic derivatives of arachidonate. Recent studies have suggested that this sequence may be involved in multiple functional responses of neutrophils (27, 3840). The possibility that such release and metabolism of arachidonate might be linked with the stimulation (in vivo or in vitro) of eosinophils is speculative but is not without support.

Stimulation of eosinophils in vitro by C5a causes a more rapid endogenous turnover of lipoxygenase-mediated arachidonate derivatives (hydroxyeicosatetraenoic acids [HETE]) (28). We recently found that arachidonic acid and two lipoxygenase derivatives, 5-HETE and 11-HETE, stimulate hexose transport in eosinophils. ${ }^{2}$ If arachidonic acid metabolism may be associated with activation of hexose transport ${ }^{2}(27)$, it might be that the elevated DOG uptake of resting EE reflects increased arachidonic acid metabolism in these cells. This speculation is supported by the observation that the net suppression of DOG uptake by NDGA correlated with the activity (DOG uptake) of resting eosinophils. Thus, the increased activity of the resting cells is related to an NDGA-inhibitable process. Although the possibility of nonspecific effects of NDGA cannot be excluded, the inhibitory effect of $10 \mu \mathrm{M}$ NDGA coincides with its ability to inhibit formation of lipoxygenase-mediated arachidonic acid derivatives by human eosinophils (28). Conversely, indomethacin, which inhibits cyclooxygenase (30), may increase production of lipoxygenase products (41), and increased DOG uptake of EE. This scheme is obviously somewhat conjectural, but it provides a hypothesis worthy of further study to clarify the activated state of eosinophils of patients with eosinophilia.

\section{ACKNOWLEDGMENTS}

We would like to thank Dr. Samuel Love for help in preparing the partially purified C5a, Ms. Sue Cousart and Ms. Pam Shirley for excellent technical assistance with some of the experiments, and Ms. Vickie Cox for typing the manuscript.

This work was supported in part by National Institutes of Health grants AI 14929, AI 09169, AI 10732, HL 16769, and a grant from the National Foundation March of Dimes.

\section{REFERENCES}

1. Saran, R. 1973. Cytoplasmic vacuoles of eosinophils in tropical pulmonary eosinophilia. Am. Rev. Respir. Dis. 108: 1283-1284.

2. Connell, J. T. 1968. Morphological changes in eosinophils in allergic disease. J. Allergy. 41: 1-9.

3. Zucker-Franklin, D. 1974. Eosinophil function and disorders. Adv. Intern. Med. 19: 1-25.

4. Tai, P. C., and C. J. F. Spry. 1976. Studies on blood eosinophils. I. Patients with a transient eosinophilia. Clin. Exp. Immunol. 24: 415-422.

5. Spry, C. J. F., and P. C. Tai. 1976. Studies on blood eosinophils. II. Patients with Loffler's cardiomyopathy. Clin. Exp. Immunol. 24: 423-434.

6. Sparrevohn, S., and H. R. Wulff. 1967. The nuclear segmentation of eosinophils under normal and pathological conditions. Acta Haematol. 37: 120-125.

7. Parrillo, J. E., and A. S. Fauci. 1978. Human eosinophils: purification and cytotoxic capability of eosinophils from patients with hypereosinophilic syndrome. Blood. 51: 457-473.

8. Ottesen, E. A., A. M. Stanley, J. A. Gelfand, J. E. Gadek, M. M. Frank, T. E. Nash, and A. W. Cheever. 1977. Immunoglobulin and complement receptors on human eosinophils and their role in cellular adherence to schistosomules. Am. J. Trop. Med. Hyg. 26: 134-141.

9. Anwar, A. R. E., and A. B. Kay. 1977. Membrane receptors for IgG and complement (C4, C3b and C3d) on human eosinophils and neutrophils and their relation to eosinophilia. J. Immunol. 119: 976-982.

10. Grover, W. H., H. H. Winkler, and D. E. Normansell. 1978. Phagocytic properties of isolated human eosinophils. J. Immunol. 121: 718-725.

11. Butterworth, A. E., J. R. David, D. Franks, A. A. F. Mahmoud, P. H. David, R. F. Sturrock, and V. Houba. 1977. Antibody-dependent eosinophil-mediated damage to ${ }^{51}$ CR-labelled schistosomula of schistosoma mansoni: 
damage by purified eosinophils. J. Exp. Med. 145: 136149.

12. Vadas, M., J. David, A. Butterworth, V. Houba, L. David, and N. Pisani. 1979. Comparison of the ability of eosinophils and neutrophils, and of eosinophils from patients with S. mansoni infection and normal individuals, to mediate in vitro damage to schistosomula of $\mathrm{S}$. mansoni. Adv. Exp. Med. Biol. 114: 677-682.

13. Boyum, A. 1964. Separation of white blood cells. Nature (Lond.). 204: 793-794.

14. Vadas, M. A., J. R. David, A. Butterworth, N. T. Pisani, and T. A. Siongok. 1979. A new method for the purification of human eosinophils and neutrophils and a comparison of the ability of these cells to damage schistosomula of Schistosoma mansoni. J. Immunol. 122: 1228-1236.

15. Gallin, J. I., J. R. Durocher, and A. P. Kaplan. 1975. Interaction of leukocyte chemotactic factors with the cell surface. I. Chemotactic factor-induced changes in human granulocyte surface charge. J. Clin. Invest. 55: 967-974.

16. Lerche, C. 1953. Electrophoresis of micrococcus pyogenes. Acta Pathol. Microbiol. Scand. 98: 1-199.

17. Brinton, C. C., and M. A. Lauffer. 1959. The electrophoresis of viruses, bacteria and cells, and the microscope method of electrophoresis. M. Brier, editor. In Electrophoresis: Theory, Methods and Applications. Academic Press, Inc., New York. 427-492.

18. McCall, C. E., D. A. Bass, M. S. Cousart, and L. R. DeChatelet. 1979. Enhancement of hexose uptake in human polymorphonuclear leukocytes by C5a. Proc. Natl. Acad. Sci. U. S. A. 76: 5896-5900.

19. Barka, T., and P. J. Anderson. 1962. Histochemical methods for acid phosphatase using hexazonium pararosanilin as coupler. J. Histochem. Cytochem. 10: 741-753.

20. DeChatelet, L. R., P. S. Shirley, L. C. McPhail, C. C. Huntley, H. B. Muss, and D. A. Bass. 1977. Oxidative metabolism of the human eosinophil. Blood. 50: 525-535.

21. Bass, D. A., L. R. DeChatelet, and C. E. McCall. 1978. Independent stimulation of chemotaxis and the hexose monophosphate shunt in polymorphonuclear leukocytes. J. Immunol. 121: 172-178.

22. Bass, D. A. 1975. Behavior of eosinophil leukocytes in acute inflammation. II. Eosinophil dynamics in acute inflammation. J. Clin. Invest. 56: 870-879.

23. Bass, D. A., T. A. Gonwa, P. Szejda, M. S. Cousart, L. R. DeChatelet, and C. E. McCall. 1980. Eosinopenia of acute infection. Production of eosinopenia by the chemotactic factors of acute inflammation. J. Clin. Invest. 65: 12651271.

24. Gallin, John I. 1980. Degranulating stimuli decrease the negative surface charge and increase the adhesiveness of human neutrophils. J. Clin. Invest. 65: 298-306.

25. Ciaraldi, T. P., O. G. Kolterman, J. A. Siegel, and J. M. Olefsky. 1979. Insulin-stimulated glucose transport in human adipocytes. Am. J. Physiol. 5: E621-E625.
26. DeChatelet, L. R., T. L. Campbell, C. E. McCall, P. S. Shirley, and C. L. Swendsen. 1980. Oxidation of 2-deoxyglucose by human polymorphonuclear leukocytes. Inflammation. 4: 249-259.

27. Bass, D. A., J. T. O'Flaherty, P. Szejda, L. R. DeChatelet, and C. E. McCall. 1980. The role of arachidonic acid in stimulation of hexose transport by human polymorphonuclear neutrophilic leukocytes. Proc. Natl. Acad. Sci. U. S. A. 77: 5125-5129.

28. Goetzl, E. J., P. F. Weller, and F. F. Sun. 1980. The regulation of human eosinophil function by endogenous monohydroxy-eicosatetraenoic acids (HETEs). J. Immunol. 124: 926-933.

29. Tappel, A. L., W. O. Lundberg, and P. D. Boyer. 1953. Effect of temperature and anti-oxidants upon the lipoxydase-catalyzed oxidation of sodium linoleate. Arch. Biochem. Biophys. 42: 293-304.

30. Flower, R. J. 1974. Drugs which inhibit prostaglandin biosynthesis. Pharmacol. Rev. 26: 33-67.

31. West, B. C., N. A. Gelb, and A. S. Rosenthal. 1975. Isolation and partial characterization of human eosinophil granules. Am. J. Pathol. 81: 575-585.

32. Bainton, D. F., and M. G. Farquhar. 1970. Segregation and packaging of granule enzymes in eosinophilic leukocytes. J. Cell Biol. 45: 54-73.

33. Bass, D. A., J. C. Lewis, and P. Szejda. 1979. Immediate activation of eosinophil lysosomal acid phosphatase by phagocytic or chemotactic membrane stimuli. Clin. Res. 27: 287A. (Abstr.)

34. Buckley, I. K. 1973. Studies in fixation for electron microscopy using cultured cells. Lab. Invest. 29: 398-410.

35. Baehner, R. L., and R. B. Johnston, Jr. 1971. Metabolic and bactericidal activities of human eosinophils. Br. J. Haematol. 20: 277-285.

36. Mickenberg, I. D., R. K. Root, and S. M. Wolff. 1972. Bactericidal and metabolic properties of human eosinophils. Blood. 39: 67-80.

37. Cramer, E. B., and J. I. Gallin. 1979. Localization of submembranous cations to the leading end of human neutrophils during chemotaxis. J. Cell Biol. 82: 369-379.

38. O'Flaherty, J. T., H. J. Showell, E. L. Becker, and P. A. Ward. 1979. Neutrophil aggregation and degranulation. Effect of arachidonic acid. Am. J. Pathol. 95: 435-444.

39. Naccache, P. H., H. J. Showell, E. L. Becker, and R. I. Sha'afi. 1979. Arachidonic acid induced degranulation of rabbit peritoneal neutrophils. Biochem. Biophys. Res. Commun. 87: 292-299.

40. Bokoch, G. M., and P. W. Reed. 1979. Inhibition of the neutrophil oxidative response to a chemotactic peptide by inhibitors of arachidonic acid oxygenation. Biochem. Biophys. Res. Commun. 90: 481-487.

41. Hamberg, M., and B. Samuelsson. 1974. Prostaglandin endoperoxides. Novel transformations of arachidonic acid in human platelets. Proc. Natl. Acad. Sci. U. S. A. 71: 3400-3404. 